E.L.U.A., 7, 1991, pp: 137-158.

\title{
ALGUNOS PRÉSTAMOS EN EL ESPAÑOL DE PANAMÁ
}

\author{
JAVIER GiRALT LATORRE \\ (Universidad de Zaragoza)
}

Cuando se habla del español de América, no se puede pasar por alto la influencia que las lenguas extranjeras han ejercido sobre él, dotándolo de una serie de préstamos que llaman la atención de aquel que se acerca a la realidad lingüística hispanoamericana. El inglés, el francés, el italiano y el portugués son las lenguas de cultura que en mayor o menor medida, y en unas zonas más que en otras, han dejado su huella en el español americano.

En este trabajo se pretende analizar en concreto algunos elementos extranjeros observados en la prensa escrita de Panamá, país centroamericano, flanqueado por el Mar del Caribe y el Océano Pacífico, y fonterizo con Costa Rica y Colombia. Panamá, por su situación y por otra serie de factores que en su momento se indicarán, no escapa a la influencia lingüística de otras lenguas, como ocurre en los demás países de Hispanoamérica y también en España.

\section{LA INFLUENCIA DEL INGLÉS.}

1.1. El influjo del inglés en el español general no ha dejado de estudiarse desde que Ricardo J. Alfaro publicara en Panamá en 1948 (en 1950 se publicó en España) su Diccionario de Anglicismos. Desde entonces han aparecido numerosos trabajos sobre los anglicismos en Hispanoamérica y en España, aportando nuevos préstamos no documentados en el Diccionario de Alfaro; porque, la realidad es que el inglés no ha dejado de influir en el español: cada día se introducen nuevos términos, nuevas acepciones y construcciones, frente a otras lenguas que han dejado de tener una presencia notable. 
La importante influencia del inglés en el español de Panamá, al igual que en el resto de los países iberoamericanos, se debe a factores diversos bien delimitados. Las vías de penetración del inglés en el español de Panamá, y que por extensión pueden ser aplicadas a los demás países de habla hispana, han sido planteadas por Elsie Alvarado de Ricord (1982: 99 y ss.). Estas vías de penetración son las que se enumeran seguidamente:

a) Las relaciones comerciales y de marketing con los Estados Unidos. No debe olvidarse que el inglés se ha convertido en la lengua del comercio, y ya no sólo en Hispanoamérica, sino en el mundo entero. Y junto a estas relaciones comerciales hay que tener en cuenta la dependencia económica de la mayoría de estos países con respecto al gran país del norte.

b) Las relaciones culturales con los Estados Unidos tienen también un peso importante. Este tipo de relaciones se establecen de dos formas: a través de las escuelas bilingües, que proliferan cada vez más en Panamá; y a través de los numerosos hispanos que realizan estudios superiores en las universidades estadounidenses.

c) La literatura científica y técnica aportan igualmente un considerable bagaje de préstamos, puesto que Estados Unidos es el centro de los avances y de las innovaciones de tipo técnico y científico. Cada novedad es aceptada generalmente con la denominación que su país de origen le dio.

d) El mundo del deporte es otra de las vías de introducción de préstamos del inglés, principalmente cuando la modalidad deportiva es importada desde E.E.U.U.

e) Los medios de comunicación actúan como aportadores y difusores de términos extranjeros, sobre todo por la traducción de las noticias llegadas a través de agencia y que generalmente aparecen redactadas en inglés. Este hecho se observa especialmente en la prensa.

1.2. Al lado de las vías de penetración comentadas anteriormente, deben añadirse otras tres para el caso concreto de Panamá. La primera es que en este país se encuentra la conocida Zona del Canal de Panamá, lo cual ha permitido la presencia norteamericana en el país desde que se concluyera la construcción del canal en 1914, y que continuará hasta 1999 de forma ininterrumpida. Sin duda alguna, el tiempo transcurrido hasta hoy ha sido suficiente para que la presencia de estadounidenses y su contacto con los habitantes de la zona hayan sido cruciales a la hora de adoptar términos ingleses. En segundo lugar, la dependencia política que Panamá ha tenido de EE.UU. para lograr su estabilidad es otro factor que interesa recordar, ya desde Torrijos, y que ha cobrado mayor vitalidad desde 1989 a raíz del derrocamiento del General Noriega por las fuerzas norteamericanas. Su presencia será ahora otra importante fuente de influencia linguística. En tercer lugar, no estará de más considerar como una vía de entrada de anglicismos el que algunos sectores sociales panameños, y posiblemente 
también en otros países, se consideren bilingües cuando la realidad lingüística de la mayoría panameña es otra. Hay panameños que hablan el inglés con orgullo, como si fuera su lengua materna, cuando en realidad es su segunda lengua (Alvarado de Ricord, 1982: 104), aunque bien es sabido que se trata de una minoría, la económicamente poderosa.

1.3. Por tanto, y como se ha tenido ocasión de comprobar, los canales de entrada del inglés en el español panameño no son pocos y este hecho dificulta frenar su entrada, por más que se tomen algunas medidas desde las instituciones oficiales e incluso desde los medios de comunicación. Esta situación se atestigua perfectamente en la prensa. Este es el motivo de que tres periódicos conformen la base documental de este trabajo: Crítica Libre con los números correspondientes al 7 y 10 de marzo de 1990, y El Siglo con el número correspondiente al 8 de marzo de $1990^{\prime}$.

Tratándose de textos escritos y no grabaciones orales, los planos lingüísticos que más interesa estudiar son el morfosontáctico y el léxico-semántico. En cuanto al plano fonético-fonológico, poco se puede deducir de los textos periodísticos que se han manejado. Sí se puede afirmar que algunos de los préstamos ingleses asumidos por el español de Panamá presentan una total adecuación a la fonética del español (shanty-chantin; rim-rines; home run-jonrones; membership -membrasías ). Hay otros casos que aparecen escritos tal y como son en inglés, y de ellos nada podemos decir desde el punto de vista fonético-fonológico porque desconocemos cuál será su pronunciación. Por tanto, el trabajo se centrará en los planos indicados más arriba y que se comentan a continuación.

\section{PLANO MORFOLÓGICO}

1.4. Aunque pudiera pensarse en un número considerable de préstamos morfológicos desde el inglés, lo cierto es que en los periódocos consultados solamente se ha documentado un caso de anglicismo morfológico, y que puede observarse en el siguiente segmento:

dias calendarios: «...y debe terminarse en noventa (90) días calendarios a partir de la fecha de la orden de proceder» (C.L. 10, p. 10)

\footnotetext{
I Las citas donde pueden localizarse los préstamos se indicarán así:

Crítica Libre del 7 de marzo: C.L. 7. p...

Crítica Libre del 10 de marzo: C.L. 10. p...

El Siglo del 8 de marzo: E.S. p...
} 
Sin duda alguna, resulta curioso observar el cambio de categoría que se ha producido, pasando a funcionar como adjetivo un sustantivo que en el español común no aparece con ese valor. Es cierto que ya desde los Siglos de Oro no es infrecuente encontrar este tipo de cambios de categoría (mujer niña, hombre veleta, hombres masa, horas punta, acuerdos marco). Sin embargo, el cambio que documentamos para la palabra calendarios es desconocido en el español general, y por ello cabe pensar en un calco de la expresión inglesa calendar day 'día civil'. Es una adaptación directa del inglés con el cambio posicional del adjetivo para adecuarla mejor a las estructuras del español. Se produce un calco morfológico manteniendo idéntica sustancia semántica.

1.5. Aparte de este anglicismo morfológico no se ha localizado ningún otro. Pero sí parece interesante comentar un aspecto relacionado con la morfología: y es que, por la aparición de determinados índices morfológicos, es posible determinar el grado de aceptación de algunos anglicismos en el español de Panamá. Es decir, el que algunos préstamos del inglés adopten rasgos morfológicos del español olvidando los de la lengua de la que proceden, es un indicativo de que han tomado carta de naturaleza en esa comunidad de habla que los adoptó, que ya se sienten como términos propios y no ajenos.

Así, en primer lugar, puede comentarse el ejemplo anterior: días calendarios. Se observará cómo el término calendarios, frente a casos como los ya apuntados (hombres masa, acuerdos marco), adopta la forma de plural en concordancia con el sustantivo que lo rige. Este hecho refleja que la expresión inglesa de la que procede está totalmente asumida por el español panameño.

En segundo lugar, se encuentran anglicismos terminados en consonante y que forman su plural con el morfema -es, tal y como lo hace el español con las palabras acabadas en consonante, y no lo forman con el morfema $-s$ como lo hace el inglés. Este es un índice de adaptación del anglicismo al nuevo medio:

buses del ingl. bus

clubes del ingl. club

galones del ingl. gallon

jonrones del ingl. home run

rines del ingl. rim

También los adjetivos ingleses que han penetrado en Panamá presentan adecuación morfológica al español. Mientras que en inglés los adjetivos son invariables para género y para número, aquellos que pasan al español como préstamos se mantienen invariables en cuanto al género, pero no en cuanto al número, creando una nueva forma mediante el morfema de plural -es : 
vernaculares del ingl, vernacular

«...harán gala de coreografías vernaculares en la comunidad de Potuga.»(C.L. 10, p. 8)

chaneles del ingl. channel

«ángulos chaneles» (C.L. 7, p. 23)

También se atestigua algún caso en el que se ha producido cambio en el género de un sustantivo al pasar del inglés al español; concretamente, se observa el paso de un masculino en inglés a femenino en español:

refrigeradoras del ingl. refrigerator

«refrigeradoras enfriando» (C.L. 10, p. 36)

Por último, se documenta la formación de nuevas palabras a partir de préstamos del inglés, derivados que confirman que se ha perdido la conciencia de que son elementos extranjeros. Los casos de nueva creación son los siguientes:

a) diminutivos, mediante el sufijo -ito :

busito del ingl. bus

«se vende busito de lujo Toyota Modelo E., año 1987»

(E.S., p. 28)

b) creación de adjetivos partiendo de sustantivos ingleses mediante el sufijo-ero (-era); en este caso forma adjetivos que denotan relación con el nombre primitivo:

softbolero del ingl. softball

«Para el torneo softbolero por la Copa Rotativa Rodríguez Moreno» (C.L. 10, p. 31)

softbolera del ingl. softball

«El segundo desafío de la jornada softbolera va dedicado al señor Ariel Castillo» (C.L. 10, p. 29)

c) creación de nuevos sustantivos a partir de sustantivos ingleses mediante el sufijo -ero ; en esta ocasión crea sustantivos aplicados a personas para denotar oficio, ocupación o afición :

tiquetero del ingl. ticket

«El tiquetero del desaparecido teatro Excelsior» (C.L. 7, p. 19) 
1.6. Por lo que respecta la plano de la sintaxis, no hay que decir mucho más que en la morfología. Solamente se van a comentar tres fenómenos de interés: a) «aún no tiene ni tres meses de haber alcanzado el poder» (C.L. 10, p. 8). Esta expresión resulta extraña para el hablante español peninsular, acostumbrado a oír en estos casos «aún no hace ni tres meses que ha alcanzado el poder», o también «no lleva ni tres meses en el poder». La explicación que se puede aducir en este caso es que se trata un calco sintáctico del inglés, concretamente de have been, equivalente a las expresiones españolas antes apuntadas. No se ha producido una readaptación de la expresión inglesa a las exigencias españolas, sino que solamente se ha dado un traducción literal, sin pensar que su contenido semántico se expresa de otra forma en nuestro idioma. Parece ser que no se da exclusivamente en Panamá, sino que está mucho más extendido, al menos por lo que se ha podido apreciar en otras fuentes de tipo oral y escrito pertenecientes a México y Venezuela.

b) «regresó en horas de la madrugada» (C.L. 10, p. 6). En este caso se observa el uso de la preposición en dentro de una expresión temporal poco frecuente en el español actual de la Península, donde se utilizaría «a altas horas de la madrugada». Sin embargo, como ya indica Cuervo $(1955, \S 394, \S 457)$, no es infrecuente en el español bogotano el uso de la preposición en por la preposición $a$, siendo este uso antiquísimo. Si por extensión se aplica esta característica al resto de Hispanoamérica, y concretamente a Panamá por su proximidad con Colombia y por su antigua vinculación histórica a este país, es posible explicar el ejemplo que aportamos por la confusión en el uso de la preposición. Además, el uso frecuentísimo en español de la preposición en para señalar el tiempo puede ser otro factor determinante para explicar la confusión (Cuervo, 1955, §394). Cabría pensar también en una posible influencia del inglés, donde solamente se emplea la preposición in en expresiones de este tipo: «in the small hours». Se habría producido un nuevo calco sintáctico en el español de América. Sin embargo, resulta aventurado plantear la posibilidad de un nuevo anglicismo, ya que se trata de un uso que se dio en el español antiguo y que, al parecer, se ha conservado en Iberoamérica.

c) «refrigeradoras enfriando» (C.L. 10, p. 36). En este ejemplo aparece el uso del gerundio tal y como lo hace el inglés, y que no se da en el español general. Quizá sea el uso sintáctico del inglés que más ha influido en el español de América, y por eso también el más estudiado. Ya Ricardo J. Alfaro indica que el uso del gerundio, como aparece en el ejemplo, es una construcción sintáctica tomada del inglés, del tipo «ley disponiendo» (1950: 224-226). También Luis Flórez señala su uso extendido en Colombia (1977: 169 y ss.). De distinta opinión es Alvarado de Ricord. Esta autora piensa que es inexacto atribuir el uso y abuso de gerundios 
a la influencia del inglés, porque algunos casos fueron considerados como problemas por los gramáticos del siglo pasado, cuando en español no tenía la prominencia que tiene hoy el lenguaje comercial (Alvarado, 1982: 105). A pesar de las palabras de Alvarado, en casos como el ejemplo apuntado sí puede pensarse en una influencia directa del inglés, y por tanto se puede seguir hablando de anglicismo sintáctico.

\section{PLANO LÉXICO-SEMÁNTICO}

1.7. Sin ningún tipo de duda, cabe afirmar que es el plano léxico el más abierto de la lengua a la influencia extranjera. Mientras que en los planos lingüísticos antes tratados se ha visto cómo el influjo del inglés se reducía a unos cuantos casos, en el vocabulario se tiene la ocasión de ver acrecentado el número de préstamos de forma considerable. De los documentados en los periódicos panameños, los hay que aparecen recogidos en los diccionarios de anglicismos o en otros tipos de trabajo, aunque no siempre atribuidos a Panamá, hecho que pone de relieve la mayor extensión de la que goza el uso de algunos términos. Hay otros que no están recogidos en ningún otro trabajo, por lo que supondrán una nueva aportación.

Se han realizado ya algunas clasificaciones de los tipos de anglicismos léxicos que pueden hallarse en el español general. La más difundida y seguida es la que presentó Ricardo J. Alfaro (1948: 115 y ss.; 1950: 16 y ss.), pero que no se seguirá en este trabajo. Interesa más en este momento la distinción que hace Juan M. Lope Blanch (1989: 261; 1989: 132-133) entre anglicismo y voz inglesa, entendiendo por el primero aquella palabra de origen inglés que ya se ha castellanizado; y por la segunda, aquella palabra de origen inglés que se sigue usando como en su lengua originaria. Naturalmente, esta distinción se limita en este trabajo a la escritura, ya que se basa en textos periodísticos.

Por otro lado, tampoco debe olvidarse que no todos los préstamos que se enumeran suponen una alteración del sistema español, ya que algunos cubren las carencias de la lengua, principalmente los que se refieren a los deportes y los que se han adaptado totalmente al español; hay otros, y no son pocos, que sí desplazan los términos propios de la lengua española para designar ciertas realidades. Sin embargo, son tan interesantes unos como otros, porque los primeros ya forman parte del sistema de la lengua en cuestion, y porque los segundos pueden llegar a tener la condición de los anteriores con el paso del tiempo.

1.8. A continuación se analizarán los préstamos ingleses localizados en las fuentes escritas de la prensa panameña ya indicadas. En cada entrada léxica se apuntarán el significado, la cita en la que aparece, su procedencia, su extensión, 
algún comentario oportuno y la bibliografía que ya documenta ese término, aunque habrá palabras que carecerán de esas referencias bibliográficas.

abanico eléctrico: ventilador; «abanico eléctrico de techo con lámpara» (E.S., p. 13); del ingl. electric fan «ventilador» (Collins). En ocasiones aparece abanico solamente sin el adjetivo, pero con idéntico significado: «abanico de pedestal», «abanico de techo cinco luces» (E.S., p. 13). Su uso es general en América española (Alfaro, 1950), aunque otros autores reducen su empleo a México, Colombia y EE.UU (Sala, 1982).

basket: baloncesto; «En disputa basket Mayor del Daríen» (C.L. 7, p. 20); forma que resulta de la aféresis del ingl. basket-ball «baloncesto» (Collins; Alfaro, 1950). Su uso es general en toda Hispanoamérica (Sala, 1982)

basquetbol: baloncesto; «Cartelera de cuatro encuentros tiene el basquetbol de la siesta de Tocumén» (C.L. 10, p. 29); castellanización del ingl. basket-ball (Collins; Alfaro, 1950). Se emplea en Iberoamérica alternando con el término español baloncesto (Sala, 1982).

blower: secador de pelo; «Centro natural Beauty ofrece curso práctico de belleza, corte y blower» (C.L. 10, p. 36); del ingl. blower «soplador» (Collins). En este caso se produce una especialización semántica del término porque, de designar de forma general un aparato generador de aire, pasa a referirse concretamente al secador de pelo en el español de Panamá.

bonus: prima, gratificación; «un contrato anual de 260 mil balboas, más un bonus de 30 mil al firmar» (C.L. 7, p. 18); del ingl. bonus «prima» (Collins).

briefing: rueda de prensa; «... caracterizó en un briefing este martes el portavoz de la cancillería soviética» (C.L. 7, p. 9); del ingl. briefing «rueda de prensa» (Collins).

bus: autobús; «...cuando bajaba de un bus en la terminal de la calle 15» (C.L. 10, p. 14); del ingl bus «autobús» (Collins; Alfaro, 1950). De empleo muy general en toda Hispanoamérica.

busito: diminutivo de bus; «se vende busito de lujo Toyota Modelo E, año 1987» (E.S., p. 28). Interesa el término por la especialización semántica que ha adquirido en Panamá, designando el autobús pequeño usado para el transporte escolar (Alfaro, 1968; Quilis, 1982).

carro: automóvil, coche; «Póngale lentes oscuras a su carro con papel ahumado» (C.L. 10, p. 40); del ingl car «automóvil» (Collins; Sala, 1982; Alfaro, 1950; Morínigo, 1966). Su uso se ha especializado en América Central, Colombia, Chile, México, Perú, Puerto Rico y Venezuela (Morínigo, 1966).

closes: armario, alacena; «se hacen trabajos de ebanistería, closes, puertas» (C.L. 10, p. 36); del ingl. closet 'armario' (Collins; Alfaro, 1950; Morínigo, 1966; Echeverri, 1964; Sala, 1982). De uso bastante extendido en Hispanoamé- 
rica.

closet: retrete; «se vende casa, tres recámaras, closet, dos baños» (E.S., p. 28); del ingl. water closet «retrete» (Collins), con aféresis del primer término de la forma compuesta, water, el más extendido en el español peninsular.

clubes: sociedad, asociación; «Esta campaña acopiadora de fondos de dicho comité, con el apoyo de los clubes cívicos y la Iglesia de San Francisco de Paul»» (C.L. 10, p. 12); del ingl. club «asociación de personas con un fin deportivo o social» (DRAE; Alfaro, 1950). el uso de club como asociación cívica parece estar mucho más extendido hoy en Hispanoamérica que en España, donde ha quedado más limitado a la designación de una sociedad deportiva.

cluch o clutch: embrague del coche; «discos de clutch», «cluch para auto» (C.L. 10, p. 38); del ingl. clutch «embrague» (Collins; Alfaro, 1950; Morínigo, 1966; Sala, 1982). Se usa en Colombia, Panamá, México, Costa Rica, Cuba, Santo Domingo, Venezuela (Quilis, 1982, 123).

cooler: nevera portátil; «cooler industrial Igloo» (E.S., p. 13); del ingl. cooler «nevera portátil» (Collins).

chaneles: acanalados; «ángulos chaneles» (C.L. 7, p. 23); del ingl. channel «acanalado, estriado» (Collins).

chantin: chabola; «... vio pasar frente al cuarto a Gertrudis que iba a su chantin» (E.S., p. 8); del ingl. shanty «choza, chabola» (Collins; Lope Blanch, 1989, 133). Este término es una variante más de la forma inglesa, junto a la variante chante documentada por Lope Blanch en el español de Puerto Rico (1989, 133).

días calendarios: días civiles; «... y debe terminarse en noventa (90) días calendarios a partir de la fecha de la orden de proceder» (C.L. 10, p. 10); del ingl. calendar day «día civil» (Collins). En el caso de calendarios puede hablarse de préstamo semántico porque es desconocido para el español común su uso con tal significado.

fríos display: frigorífico con escaparate; «fríos display para carnicería» (C.L. 7, p. 22); del ingl. display «exposición, presentación» (Collins).

duplex: vivienda para dos familias; «Vendo duplex en campo Limbher, 3 recámaras, 2 baños, sala comedor, terraza» (E.S., p. 28); del ingl. duplex «casa para dos familias», tratándose de un uso del inglés norteamericano y no del británico (Collins).

freezer: congelador; «Reparamos enseguida: lavadoras, refrigeradoras, freezer» (C.L. 10, p. 36); del ingl. freezer «congelador» (Collins). En Puerto Rico se emplea para designar el refrigerador o la heladera eléctrica (Morínigo, 1966). También se usa en Chile (Sala, 1982).

full equipo: equipo completo; «Se vende busito de lujo Toyota Modelo E., año 1987, full equipo Sun Roof» (E.S., p. 28); del ingl. full «completo» (Collins). Luis Flórez documenta idéntico uso en Colombia $(1977,182)$.

galones: medida inglesa de capacidad para los líquidos, usada en el comercio. 
Equivale a 4' 5 litros. (DRAE); «Instalaron un tanque con capacidad de diez mil (10.000) galones de agua» (C.L. 10, p. 11): del ingl. gallon (DRAE; Collins). Aunque se trata de un término recogido por el DRAE, lo cierto es que no se emplea en España.

hits: golpe certero; «Panamá Metro, 16 carreras, 21 hits, 3 errores y 10 dejadas en base» (C.L. 10, p. 34); del ingl. hit «golpe certero en béisbol» (Collins). Su uso se atestigua también en Colombia y Chile (Sala, 1982), lo que significa que debe ser mucho más general en Hispanoamérica.

hot dog: perrito caliente, emparedado de salchicha; «Se buscan dos personas para la venta de hot dog» (C.L. 10, p. 36); del ingl._hot dog «perrito caliente» (Collins; Alfaro, 1950; Morínigo, 1966). La expresión se utiliza en Iberoamérica, aunque está más extendida la versión española «perrito caliente». Alfaro lo considera un vulgarismo norteamericano, e indica que es más aceptable el provincialismo aragonés camorra catalogado y definido por la Academia así: «panecillo largo con un trozo de longaniza dentro» $(1950,333)$. Aun con todo, su extensión no se ha podido frenar.

hot pants: pantalón corto; «... siempre se encaleta un hot pants» (C.L. 10, p. 9); del ingl. hot pants (que equivale a shorts) «pantalones cortos» (Collins). Sala atribuye su uso a México (1982).

implementar: 1levar a cabo una acción; «.... con el propósito de implementar un agresivo plan de trabajo que permita la recuperación de los préstamos agropecuarios morosos» (C. L. 10, p. 14); del ingl. to implement «realizar, ejecutar» (Collins; Alfaro, 1950; Morínigo, 1966; Sala, 1982). Su empleo se extiende por toda Hispanoamérica y también empieza a oirse en España.

implementación: ejecución de una labor: «... porque a veces los problemas no son tanto de procedimiento, sino de los individuos que tienen que llevar adelante la implementación de los procedimientos» (C.L. 10, p. 17); del ingl. implementation «realizacion, ejecución» (Collins). Por lo que se ha observado en la bibliografía consultada, parece que su uso no está tan extedido como el de su verbo implementar.

investigativo: investigador; «La APEICAP se propone de esta forma, profundizar el fortalecimiento del quehacer profesional académico e investigativo del administrador público panameño» (C.L. 10, p. 13); del ingl. investigative «investigador» (Collins).

jonrón, jonrones: término deportivo que indica la carrera completa de un jugador de béisbol; «... con espectacular jonrón de Ezequiel Quintero», «son jonrones dramáticos» (ambos ejemplos en C.L. 10, p. 34); del ingl. home run «carrera completa en béisbol» (Collins; Alfaro, 1950). El empleo de este término es general en los países hispanoamericanos.

king size: de tamaño extra; «se vende refrigeradora congelador dos puertas, cama caoba $3 / 4$, agua, king size» (C.L. 10, p. 23); del ingl. king size «tamaño 
extra» (Collins).

kit: equipo, elementos que conforman algo; «kit de carburador» (C.L. 10, p. 38); del ingl. kit «equipo, avíos» (Collins).

loby: vestíbulo; «Elegante loby, sala, comedor, terraza integrada» (E. S., p. 14); del ingl. lobby «vestíbulo» (Collins; Alfaro, 1950; Sala, 1982).

look: aspecto de la persona; «Deseas cambiar tu look?» (C.L.7, p. 22); del ingl. look «aspecto» (Collins). Es una voz inglesa que empieza a gozar de cierta vitalidad, incluso en España.

master: principal; «master cilindro» (C.L. 10, p. 38); del ingl. master «maestro, principal» (Collins).

membresías: abonos, lo que permite acceder a la calidad de miembro o socio; «Inauguración: grandes ofertas. Esta semana membresías gratis» (E.S., p. 26); del ingl. membership «calidad de miembro» (Collins). Se utiliza también en México (Collins).

money orders: giro postal; «money orders, giros, pagarés» (E. S., p. 31); del ingl. money orders «giro postal» (Collins; Alfaro, 1950). Sala atestigua su uso en Puerto Rico (1982).

nocaut: dejar fuera de combate o de juego, según se use e boxeo o en béisbol; «...derrotándolo por la vía del nocaut en el séptimo asalto» (C.L. 10, p. 32); «La regla del nocaut que rige en estos campeonatos» (C.L. 10, p. 34); del ingl. knockout «dejar fuera de combate» (Collins; Alfaro, 1950; Morínigo, 1966; Sala, 1982).

pikcup: camioneta de reparto; «se vende pickup Kia Motors» (E.S., p. 28); del ingl. pickup «camioneta» (Collins; Alfaro, 1950; Morínigo, 1966; Sala, 1982). Según Quilis (1982, 129-130), se trata de un pequeño camión de dos ejes en Costa Rica, Guatemala y Panamá; en Perú es un camión de tres ejes; en Puerto Rico, México y Guatemala también es un pequeño camión para pesaje y carga. En Colombia se utiliza el préstamo con esta última acepción (Echeverri, 1964). pitcheo: lanzamiento (en béisbol); «En pitcheo, el Chiricano Alvaro 'La Pólvora' Hernández fue el mejor con 3-0» (C.L. 7,p. 18); del ingl. pitch «lanzamiento», del verbo to pitch «lanzar» (Collins). Alfaro indica que se trata de un derivado de pitcher «lanzador en el juego de béisbol» (1950,334). Sala limita su uso a Cuba, Chile y México (1982).

ponchar: perforar, agujerear (al bateador en el béisbol); «Ponchar a un bateador» (C.L. 10, p. 34); del ingl. to punch «agujerear» (Collins; Morínigo, 1966). Alfaro propone una procedencia de to puncture «pinchar, agujerear» $(1950,343)$. Presenta un uso general en América Central (Sala, 1982), pero no con este uso tan específico del béisbol.

prity-boys: el hombre guapo que alardea de su belleza, conquistador, pero sin oficio ni beneficio; «... porque preferiría ser concubina de profesional, aunque feo, que de un prity-boys» (C.L. 10, p. 9); forma compuesta por los términos 
ingleses pretty «guapo, bello», y boy «muchacho» (Collins); la unión de ambos elementos forma un compuesto con un nuevo significado para Panamá.

record policivo: antecedentes penales; «...con experiencia, record policivo, carnet de salud» (C.L. 10, p. 36); del ingl. police record «antecedentes penales, historial policíaco» (Collins; Alfaro, 1950; Sala, 1982).

refrigeradoras: neveras; «Refrigeradoras enfriando» (C.L. 10, p. 29); del ingl. refrigerator «nevera, refrigerador» (Collins; Alfaro, 1950; Morínigo, 1966). Se emplea en toda Hispanoamérica.

rines: llanta del automóvil; «rines de hierro» (C.L. 10, p. 29); del ingl. rim «llanta» (Collins; Alfaro, 1950). Su uso se documenta en Colombia, Costa Rica, Cuba, Ecuador, México y Venezuela, además de Panamá (Quilis, 1982; Sala, 1982).

softbol: también llamado bola suave, especie de béisbol en terreno más pequeño que el normal, con pelota grande y blanda (Morínigo, 1966); «Finalizó la liga interbancaria de softbol» (C.L. 10, p. 29); del ingl. soft-ball «bola suave» (Collins; Morínigo, 1966; Sala, 1982). En ocasiones, y para referirse al mismo concepto, solamente aparece el primer término de la forma compuesta, soft: «Jornada de tres partidos en soft de Tocumén mañana» (C.L. 10, p. 29).

softbolero, softbolera: relativo o perteneciente al softbol; «Para el torneo softbolero por la Copa Rotativa Rodrigo Moreno» (C.L. 10, p. 31), «El segundo desafío de la jornada softbolera va dedicada al señor Ariel Castillo» (C.L. 10, p. 29). Derivados de softbol ${ }^{2}$

sparring-patner: entrenador de boxeo; «... quien le viene sirviendo de sparring-patner al hoy titular mundial pluma-junior» (C.L. 10, p. 32); del ingl. sparring-patner «entrenador de boxeo» (Collins; Sala, 1982). Lo más frecuente es el uso de sparring solamente.

split: abertura, hendedura; «Albañilería, aires acondicionados de ventana y split, trabajos garantizados» (C.L. 10, p. 36); del ingl. split «abertura» (Collins)

spring: muelle; «spring chico», «spring grande» (C.L. 10, p. 38); del ingl. spring «muelle del automóvil» (Collins; Alfaro, 1950). Quilis solamente atestigua este uso en Panamá, tanto para designar muelles en general, como muelies de asiento en el automóvil. Además, recoge formas totalmente asimiladas por el español panameño: esprines $(1982,120 \mathrm{y} \mathrm{ss}$.$) .$

strike: término del juego del béisbol: indica la situación que se produce cuando el pitcher ha lanzado la pelota tres veces seguidas sin que el bateador haya podido pegarle ninguna de ellas (Sala, 1982); «Se pasó tirando bolas. No metió un strike» (C.L. 10, p. 2); del ingl. strike «golpe» (Collins). De uso general en todos aquellos países en los que se practica el béisbol.

team: equipo; «Las nuevas indagatorias rendidas por el team de hombres que realizaron el operativo de captura de la frontera» (E.S., p. 21); del ingl. team «equipo de hombres» (Collins; Alfaro, 1950; Sala, 1982; Morínigo, 1966; Echeverri, 1964). Su uso se extiende por todos los países de habla hispana.

tips: pronóstico; «tips para hoy jueves» (E.S., p. 26); del ingl. tip «aviso, indicación, pronóstico» (Collins; Alfaro,

2 Véase también el apartado 1.5 . b) de este mismo trabajo. 
1950).

tiquetero: encargado de perforar boletos; «El tiquetero del desaparecido Teatro Excelsior» (C.L. 7, p. 19); derivado de ticket «boleto» (Collins). Se emplea también en zonas de habla hispana de EE.UU. (Sala, 1982) ${ }^{3}$.

vernacular, vernaculares: vernáculo. propio; «...harán gala de las coreografías vernaculares en la comunidad de Potuga», «...dará paso al programa de esta noche vernacular» (ambos ejemplos en C.L. 10, p. 8); del ingl. vernacular «vernáculo, indígena, propio» (Collins; Alfaro, 1950).

welter: Iuchador o pugilista con un peso de $67 \mathrm{~kg}$. aproximadamente (Morínigo, 1966); «... perdiendo por la vía del nocaut en la división welter» (C.L. 7, p. 20); del ingl. welter-weight «luchador entre 135 y 145 libras» (Collins; Alfaro, 1950; Sala, 1982).

winch: montacargas de camión; «Camión completo con plataforma, tres ejes, winch» (E.S., p. 11); del ingl. winch «cabestrante, torno» (Collins). Con este mismo valor se utiliza en Puerto Rico según indica E. Mellado de Hunter (1981, 103).

yes man: expresión que se aplica a aquel que dice a todo que sí (Fernández García, 1972); «El candidato presidencial norieguista Carlos Duque junto al pusilánime 'yes man' Espino» (E.S., p. 23); forma compuesta por los términos ingleses yes «sí» y man «hombre», y que se utiliza en Panamá de forma despectiva.

\section{LA INFLUENCIA DEL FRANCÉS.}

2.1. En la prensa panameña se ha observado también la presencia de algunos préstamos del francés. Sin embargo, los galicismos documentados se presentan en un número mucho más reducido que los anglicismos, aunque el francés sea una de las lenguas europeas con una presencia importante en la lengua española. Esta circunstancia no debe de extrañar en el caso de Panamá (y seguramente tampoco en el resto de los países hispanoamericanos), ya que, para que se produzca una influencia como la del inglés, deben darse las condiciones favorables que antes se analizaron, y éstas no se dan para el francés. Como consecuencia de ésto, no todos los galicismos serán de adopción reciente, como ocurría con los préstamos ingleses, sino que algunos datan de siglos anteriores según indican los diccionarios. Hay algún caso que no aparece incluido en ningún tipo de trabajo y que supondrá una nueva aportación para conocer la importancia del francés en la configuaración del español de Panamá y el de América en general.

\footnotetext{
${ }^{3}$ Véase en este caso al apartado 1.5. c) de este mismo trabajo.
} 
2.2. Los galicismos localizados en los periódicos consultados son puramente léxicos y su fonética está totalmente adaptada a la española, al menos por lo que podemos deducir a través de la ortografía. Son los siguientes:

afiche: cartel o aviso público fijado en las calles y plazas en forma visible, generalmente con dibujos y letreros llamativos (Morínigo, 1966); «... las damas en mención están haciendo circular un afiche alusivo a la oración de la celebración de La Cuaresma» (C.L. 10, p. 7); del francés affiche «anuncio oficial o publicitario colocado en un lugar público» (GLLF). Según Morínigo (1966), su uso es general en Argentina, Perú y Uruguay; Sala (1982) lo extiende a colombia, Cuba y Chile.

contralor: en algunos países de América, funcionario encargado de examinar las cuentas y la legalidad de los gastos públicos (DRAE); «Indecisa asamblea sobre nombramiento del contralor» (C.L. 7, p. 13); del francés contrôleur «controlador», derivado a su vez de contrôler y contrôle. Se introduce en España en el siglo XVI como un cargo honorífico; pero, hoy, y por lo que conocemos, ha dejado de usarse en la Península (ELH; DCECH). Sin embargo, en algunos países de Hispanoamérica es un cargo administrativo de suma importancia, aunque Morínigo lo considera solamente término argentino (1966). Alfaro señala que contralor equivale a comptroller o controller del inglés y al contrôleur francés (1950, 143-144).

contraloría: en algunos países de América, servicio encargado de examinar la legalidad y corrección de los gastos públicos (DRAE); «Partida general de 20 mil balboas fue aprobada por la Contaloría General de la República» (C.L. 10, p. 15). Es un derivado de contralor, lo que nos pone de manifiesto que el galicismo está totalmente asumido por el español de Panamá.

gendarmería: cuerpo de tropa de los gendarmes (DRAE); «La incredibilidad política [...] fue el fantasma de la adversidad al que ni con las armas pudo vencer la élite de la gendarmería» (C.L. 10, p. 4); del francés gendarmerie «cuerpo militar encargado de velar por la seguridad pública» (GLLF). Parece ser que el empleo de este término no está muy extendido en Hispanoamérica al no aparecer recogido en los trabajos y en los diccionarios consultados.

matinée: espectáculo teatral, circense o cinematográfico que se of rece al público por la mañana o en las primeras horas de la tarde (Morínigo, 1966); «matinée a las 4:00 de la tarde» (C.L. 10, p. 7); del francés matinée «función de tarde» (GLLF; Collins). Usado generalmente en Hispanoamérica (Sala, 1982), pero anticuado ya en España.

rol: papel que un actor representa; «... cuyo rol estelar masculino será interpretado por el aplaudido comediante Enrique Olivella» (C.L. 10, p. 7); del francés rôle «papel que se desempeña; papel de una pieza dramática» (GLLF); este 
mismo uso se da en inglés (Collins). En España se emplea el término rol para referirnos al papel que uno debe desempeñar en una misión, en un trabajo, pero no para hacer referencia al papel de un actor en una pieza dramática. Por este motivo, podría hablarse en Hispanoamérica de galicismo semántico a causa de ese uso más específico del término.

rosticero: aparato que sirve para asar carnes o pollos; «Vendo rosticero de 20 pollos» (E.S., p. 29); derivado de rosticería «establecimiento donde se asan y venden carnes»; la derivación se produce mediante el sufijo -ero, que en nombre de cosa significa objeto destinado a un cierto fin. Sobre el origen de rosticería hay dos posturas: para unos procedería del francés rôtisserie (GLLF; Morínigo, 1966); para otros, del italiano rosticceria (DRAE). Además de Panamá, es término propio de México y Nicaragua (Sala, 1982).

2.3. Por último, no debe olvidarse la existencia de los llamados galo-anglicismos, es decir, aquellos términos tomados del inglés, pero que son de procedencia francesa (Beardsley, 1979: 9-10). De entre todas las voces analizadas, hay una que posiblemente responda a la descripción del galo-anglicismo. Se trata del término morgue «depósito de cadáveres». La cita en la que aparece es la siguiente: «El instituto de medicina legal necesita urgentemente una morgue propia» (E.S., p. 23). Según M. Sala (1982), esta palabra es de procedencia francesa; pero, también es cierto que en EE.UU. se utiliza con idéntico significado. Esto lleva a pensar en un préstamo del inglés, aunque el origen último de la palabra sea francés. En definitiva, podría pensarse en un galo-anglicismo. Este término se usa en Argentina, Colombia, Cuba, EE.UU. y México (Sala, 1982); es necesario añadir también que se emplea en toda la América Central (Collins).

\section{TÉRMINOS DE ORIGEN INCIERTO.}

3.1. Se incluyen en este apartado una serie de palabras cuya procedencia concreta no está determinada. Puede ser interesante hacer notar su existencia y su uso en el español de Panamá.

Siguiendo un orden alfabético como hasta ahora, se documenta en primer lugar la palabra balina (C.L. 10, p. 38). En este caso puede pensarse en un posible origen italiano, en la procedencia de pallina «bolita» (NDSI). Puesto que la palabra se encuentra en un contexto donde se enumeran elementos del automóvil, es posible que la forma balina haga referencia al cojinete de bolas por la extensión de su significado. Cabe señalar también la posibilidad de que el término surja a partir de balín, como forma que designa aquellas balas en forma de bolitas, y que posteriormente se haya extendido su significado hasta designar el cojinete. Pero esta cuestión es una simple hipótesis que no se puede comprobar 
en estos momentos.

Mucho más clara en este sentido es la voz balinera (C.L. 10, p. 38), que se habría formado a partir de balina mediante el sufijo - era, indicando de esta manera un objeto que contiene balinas o bolitas. Así, balinera se referiría de forma más precisa al cojinete de bolas. Además, en su formación y uso ha podido ejercer una impotante influencia la voz inglesa ball-bearing «cojinete de bolas» (Collins), forma compuesta donde aparece el elemento ball «bola». este hecho ha podido determinar que se especialice el uso de balinera y balina para designar el cojinete de bolas del automóvil.

Otro de los términos interesantes es bambinazo: «Para series a dos vueltas, el record actual es de 8 bambinazos» (C.L. 7, p. 18). Por el contexto parece ser que hace referencia a un tipo de jugada o de golpe en el juego del béisbol. Si se tiene en cuenta la procedencia del deporte en cuestión, habrá que optar por una posible procedencia inglesa, y se tratará de un derivado del verbo inglés to bump «golpe, agitación» (Collins). Pero también se puede apuntar la existencia en portugués de un verbo bambinar con el mismo significado que el inglés (DPE). Esto también puede hacer pensar en un origen portugués del término, aunque parece más acertado inclinarse por el origen inglés.

De igual modo, se atestigua la voz citadino «ciudadano»: «sectores citadinos y de las afueras» (C.L. 7, p. 13). La dificultad en este caso no está tanto en averiguar su procedencia, sino en atribuirla definitivamente al italiano o al francés. M. Sala (1982) la considera de origen italiano, concretamente de cittadino. Pero también puede postularse un origen francés, de la voz citadin, y que a su vez procede del italiano cittadino (GLLF). Puesto que en ambos casos se propone un origen italiano, no será aventurado inclinarse por un influjo del italiano y no del francés. Es un término que también se emplea en Venezuela (Sala, 1982).

También nos encontramos con la voz movi en el siguiente contexto: «Hoy iban al juzgado a arreglar el movi» (E.S., p. 8). Su significado parece ser el de «asunto», y por ello quizá se pueda aducir una procedencia del inglés move «movimiento, acción, gestión» (Collins).

Por último, tampoco aparece recogida en otros trabajos la palabra paciero: «Un paciero acholado aficionado a las jaibas» (E.S. 8, p. 8). Por el contexto en el que aparece, la palabra tiene el significado de «comedor, tragón, glotón». Según esto, en el italiano encontramos el verbo pacchiare «comer a dos carrillos» (NDSI), y su derivado pacchierotto «gordinflón» (NDSI). La conclusión a la que llegamos es la probable procedencia italiana del término paciero, totalmente adaptado el español panameño. 


\section{CONSIDERACIONES FINALES.}

4.1. A la vista de los datos aportados hasta este momento, en primer lugar, hay que decir que la influencia del inglés se inpone a la de cualquier otra lengua. De un total de 76 préstamos documentados en tres periódicos de Panamá, 64 son de origen inglés, lo que supone un $84^{\prime} 22 \% ; 8$ son de procedencia francesa, lo que representa un $10.52 \%$; y 4 pueden ser considerados de procedencia italiana, lo que equivale al 5,26\% del total. Esta serie de porcentajes reafirma la idea de que es la lengua inglesa la que más influye en el español de Panamá y la que lo sigue haciendo con mayor vitalidad. El inglés es la lengua que aporta un mayor número de palabras al léxico panameño, e incluso extiende su influencia al plano morfosintáctico, aunque en menor medida.

El influjo del francés es mucho menos notable, apenas contribuye con unos pocos galicismos dentro del plano léxico y no otro. Además, algunos de ellos han podido afianzar su vitalidad a través del propio español, y posteriormente han caido en desuso en España, mientras que en Panamá y en buena parte de Hisopanoamérica se han mantenido con fuerza.

Y la presencia del italiano es mucho menor en comparación con las dos lenguas anteriores; pero esos cuatro italianismos que se documentan pueden ser indicio de que la presencia de péstamos del italiano en el español de Panamá es mayor de lo que reflejan los periódicos consultados.

4.2. Resulta interesante también observar en qué campos semánticos abundan más los préstamos que se han comentado. El campo semántico en el que se atestigua el mayor número de extranjerismos es el referente a la vida social. Pero hay que advertir que dentro de éste deben diferenciarse una serie de subcampos: el mundo de la administración (días calendarios, record policivo, contralor, contraloría, gendarmería), el mundo del espectáculo (tiquetero, matinée, rol), medios de comunicación (afiche, briefing, tips), servicios sociales (clubes, implementar, implementación, team, money orders, morgue, movi). Un número considerable de préstamos nos aporta en campo semántico del deporte (basket, basquetbol, bonus, jonrón, pitcheo, ponchar, softbol, softbolero, softbolera, sparring-patner, strike, welter, nocaut). Tampoco es nada despreciable el número de voces referentes al mundo del automóvil y sus accesorios (bus, busito, carro, cluch, pickup, rines, spring, winch, balina, balinera). No se quedan atrás los referentes a la vivienda y a los electrodomésticos (abanico eléctrico, loby, closes, closet, cooler, chaneles, chantin, duplex, freezer, display, refrigeradora, split, rosticero). Por último, se encuentran algunos campos semánticos con muy pocos ejemplos: la alimentación (hot dog), medidas (galones), el cuidado personal (look, blower, hot pants). Y no debe olvidarse la importante presencia de adjetivos referentes a distintas realidades (investigativo, vernacular, citadinos, 
full, paciero, master).

Como se puede comprobar, la mayor concentración de los préstamos se produce en los campos semánticos que se refieren a lo más cotidiano y ususal de la vida de un país: el deporte, el coche, la casa, los electrodomésticos. Pero el extranjerismo también penetra en otros campos semánticos, aunque con menor fuerza, lo que nos indica que el préstamo no se ve limitado cuando se introduce en una lengua extraña.

4.3. La diversidad de los campos semánticos permite llegar a otra consideración, y es que la mayoría de los préstamos documentados deben gozar de cierta vitalidad en el español panameño, porque un buen número aparece en las secciones más leidas por el público. Su empleo en la prensa implica que la mayor parte de los lectores comprende dichos términos, aunque sin tener conciencia de que están emplenado elementos ajenos a su propia lengua. Esta idea no es aceptada por todos los autores porque la gente que accede a la lectura de los periódicos es una minoría, sobre todo en determinadas zonas de Iberoamérica donde hay un alto índice de analfabetismo, y este hecho impide afirmar que el uso y conocimiento de los préstamos sea general. Lo que sí debe quedar claro es que la mayoría de los préstamos analizados deben ser usados en muchos más países de los que se indican en este trabajo y en los consultados. Sólo el hecho de que se den en Panamá cuando ningún otro estudio lo indicaba, es un dato suficiente para pensar en una mayor extensión del uso de esas voces.

4.4. Sobre la naturaleza de los préstamos, hay que indicar que unos son de transmisión oral, lo cual se puede apreciar fundamentalmente en la adecuación que presentan a la ortografía y a la pronunciación española (chantin, implementar, movi, carro, rines, membrasía, galones, paciero, contralor, afiche, etc); otros son de transmisión escrita, hecho que se comprueba en que su ortografía no varía en nada de la de su idioma de origen (look, blower, hot pants, split, winch, matinèe, briefing, pickup, etc).

4.5. Adecuando siempre las afirmaciones a lo que puede dar de sí un estudio tan limitado, puede decirse que la estructura básica del español no se ha visto afectada tal y como ya lo indicaba Ven Serna (1970: 845). Pero después de analizar los extranjerismos, sí puede concluirse que la mayoría suple a los términos propios del español para designar esas mismas realidades. Cierto es que la Academia Panameña de la Lengua procura preservar la pureza del español mediante diversas acciones de tipo cultural, y que los medios de comunicación secundan esa labor de prevención en la medida de lo posible (Alvarado de Ricord, 1982: 102 y ss.). Pero es verdaderamente difícil, y principalmente en la prensa, evitar el uso de anglicismos en las secciones de deportes, de anuncios por 
palabras y en las noticias llegadas a través de agencia.

En definitiva, y ante el préstamo lingüístico, no se debe optar por una postura de rechazo radical. Como dice Alvarado de Ricord (1982: 105), «la lengua española absorberá y asimilará las palabras necesarias, enriqueciéndose por ello». Eso sí, intentando mantener siempre entre los hispanohablantes la unidad lingüística. Pero no estará de más tener una actitud vigilante ante la invasión de extanjerismos, intentando localizar el espacio en el que se producen y la clase social que los acomete. Y en esta tarea debe jugar un papel fundamental la prensa, la publicidad y los medios de comunicación en general, recurriendo lo menos posible al préstamo; al fin y al cabo, son los que acaban moldeando la conducta de las masas (E. Lorenzo, 1990: 79).

\section{Referencias bibliográficas}

ALFARO, Ricardo J. (1948): «El anglicismo en el español contemporáneo», Boletin del Instituto Caro y Cuervo IV, pp. 102-128.

ALFARO, Ricardo J. (1950): Diccionario de anglicismos, Madrid, Gredos.

ALFARO, Ricardo J. (1968): Panameñismos, Publicaciones de la Academia Panameña de la Lengua.

ALVARADO DE RICORD, Elsie (1982): «The impact of English in Panama», Word, 33, 1982, pp. 97-108.

BEARDSLEY, T.S. (1979): «Los galo-anglicismos», Boletín de la Academia Norteamericana de la Lengua, 4-5, pp. 19-26.

COLLINS (1990): Collins. Diccionario español-inglés, English-Spanish, Barcelona, Grijalbo.

CUERVO, Rufino J. (1955): Apuntaciones críticas sobre el lenguaje bogotano, Bogotá, Instituto Caro y Cuervo, $9^{\circ} \mathrm{ed.}$

DCECH (1980-1983): Joan Corominas y J.A. Pascual, Diccionario críticoetimológico castellano e hispánico, Madrid, Gredos.

DPE (1960): Diccionario de português-espanhol, Oporto.

DRAE (1970): Real Academia Española, Diccionario de la lengua española, Madrid, Espasa-Calpe, $19^{\circ} \mathrm{ed}$.

ECHEVERRI, Oscar (1964): «Anglicismos, galicismos y barbarismos de frecuente uso en Colombia», Presente y Futuro de la Lengua Española, Madrid, OFINES, pp. 91-101.

ELH (1960-1967): Enciclopedia Lingüística Hispánica. T. II: Elementos constitutivos del español, dirigida por M. Alvar, A. Badía, R. Balbí y L.E. Lindley, Madrid, CSIC.

FERNANDEZ GARCIA, A. (1972): Anglicismos en el español, Oviedo. 
FLOREZ, Luis (1977): Apuntes de español, Bogotá, Instituto Caro y Cuervo. GLLF (1978): Grand Larousse de la Langue Française, Paris.

LOPE BLANCH, Juan M. (1989): «Anglicismos en el español de California», Revista Canadiense de Estudios Hispánicos, XIII, 2, pp. 261-267.

LOPE BLANCH, Juan M. (1989): «Anglicismos en el español del suroeste de EE.UU.», Actas del IX Congreso Internacional de Hispanistas, Frankfurt, pp. 131-138.

LORENZO, Emilio (1990): «Anglicismos en el español de América», El idioma español en las agencias de prensa, Fundación Germán Sánchez Ruipérez y Agencia EFE, Madrid, pp. 65-82.

MALARET, Augusto (1955): Vocabulario de Puerto Rico, New York.

MELLADO DE HUNTER, Elena (1981): Anglicismos profesionales en Puerto Rico, Universidad de Puerto Rico.

MONTES, J.J. (1985): «Calcos recientes del inglés en el español», Boletín del Instituto Caro y Cuervo ${ }_{2}$ XL, pp. 17-50.

MONTES, J.J. (1976): «Otros calcos del inglés: evidencia y algunos más», Boletín del Instituto Caro y Cuervo, XXXI, pp. 430-441.

MORINIGO, Marcos A. (1966): Diccionario de americanismos, Buenos Aires

NDSI (1973): Nuovo Dizionario Spagnolo-Italiano, Italiano-Spagnolo, Turín, $7^{\circ} \mathrm{ed}$.

QUILIS, Antonio (1982): «Léxico relacionado con el automóvil en Hispanoamérica y en España», Anuario de Letras, UNAM, v. XX, pp. 115-144.

SALA, Marius (1982): El español de América. Léxico, Bogotá, Instituto Caro y Cuervo, $2 \mathrm{v}$.

SERNA, Ven (1970): «Breve examen de unos anglicismos recientes», Actas del III Congreso Internacional de Hispanistas, México, pp. 839-846.

STONE, Howard (1987): «Los anglicismos en España y su papel en la lengua oral», Revista de Filología Española, XLI, pp. 141-160.

\section{6. ÍNDICE DE VOCES ${ }^{4}$.}

abanico: 1.8

abanico eléctrico: $1.8 ; 4.2$

afiche: $2.2 ; 4.2 ; 4.4$

affiche: $2.2 ; 4.2$

balina: $3.1 ; 4.2$

${ }^{4}$ Los números que aparecen junto a cada una de las voces remiten a los apartados de este trabajo donde pueden ser localizadas. 
balinera: $3.1 ; 4.2$

ball-bearing: 3.1

bambinar: 3.1

bambinazo: 3.1

bump (to): 3.1

baloncesto: 1.8

basket: $1.8 ; 4.2$

basquetbol: $1.8 ; 4.2$

basket-ball: 1.8

blower: $1.8 ; 4.2 ; 4.4$

bola suave: 1.8

bonus: $1.8 ; 4.2$

briefing: $1.8 ; 4.2 ; 4.4$

bus: $1.5 ; 1.8 ; 4.2$

buses: 1.5

busito: $1.5 ; 1.8 ; 4.2$

calendar day: $1.4 ; 1.8$

camorra: 1.8

car: 1.8

carro: $1.8 ; 4.2 ; 4.4$

citadin: 3.1

citadinos: $3.1 ; 4.2$

cittadino: 3.1

closes: $1.8 ; 4.2$

closet: $1.8 ; 4.2$

club: $1.5 ; 1.8$

clubes: $1.5 ; 1.8 ; 4.2$

cluch o clutch: $1.8 ; 4.2$

comptroller: 2.2

contralor: $2.2 ; 4.2 ; 4.4$

contraloría: $2.2 ; 4.2$

contrôler: 2.2

contrôleur: 2.2

controller: 2.2

cooler: $1.8 ; 4.2$

chaneles: $1.5 ; 1.8 ; 4.2$

channel: $1.5 ; 1.8$

chante: 1.8

chantin: $1.8 ; 4.2 ; 4.4$

días calendarios: $1 . .4 ; 1.5 ; 1.8 ; 4.2$

display: $1.8 ; 4.2$ duplex: $1.8 ; 4.2$

electric fan: 1.8

esprines: 1.8

freezer: $1.8 ; 4.2$

full: $1.8 ; 4.2$

gallon: $1.5 ; 1.8$

galones: $1.5 ; 1.8 ; 4.2 ; 4.4$

gendarmería: $22 ; 4.2$

gendarmerie: 2.2

have been: 1.6

hits: 1.8

home run: $1.5 ; 1.8$

hot dog: $1.8 ; 4.2$

hot pants: $1.8 ; 4.2 ; 4.4$

implement (to): 1.8

implementación: $1.8 ; 4.2$

implementar: $1.8 ; 4.2 ; 4.4$

implementation: 1.8

investigative: 1.8

investigativo: $1.8 ; 4.2$

jonrón: $1.8 ; 4.2$

jonrones: $1.5 ; 1.8$

king size: 1.8

kit: 1.8

knock-out: 1.8

loby: $1.8 ; 4.2$

look: $1.8 ; 4.2 ; 4.4$

master: $1.8 ; 4.2$

matinée: $2.2 ; 4.2 ; 4.4$

membership: 1.8

membrasías: $1.8 ; 4.4$

money orders: $1.8 ; 4.2$

morgue: $2.3 ; 4.2$

move: 3.1

movi: $3.1 ; 4.2 ; 4.4$

nocaut: $1.8 ; 4.2$

pacchiare: 3.1

pacchierotto: 3.1

paciero: $3.1 ; 4.2 ; 4.4$

pallina: 3.1

pickup: $1.8 ; 4.2 ; 4.4$ 
pitch (to): 1.8

pitcheo: $1.8 ; 4.2$

pitcher: 1.8

police record: 1.8

ponchar: $1.8 ; 4.2$

prity-boys: 1.8

punch (to): 1.8

puncture: 1.8

record policivo: 1.8

refrigeradoras: $1.5 ; 1.6 ; 1.8 ; 4.2$

refrigerator: $1.5 ; 1.8$

rim: $1.5 ; 1.8$

rines: $1.5 ; 1.8 ; 4.2 ; 4.4$

rol: $2.2 ; 4.2$

rôle: 2.2

rôtisserie: 2.2

rosticceria: 2.2

rosticero: $2.2 ; 4.2$

shanty: 1.8

shorts: 1.8

soft: 1.8

soft-ball: $1.5 ; 1.8$

softbol: $1.8 ; 4.2$

softbolero: $1.5 ; 1.8 ; 4.2$

softbolera: $1.5 ; 1.8 ; 4.2$

sparring-patner: $1.8 ; 4.2$

split: $1.8 ; 4.2 ; 4.4$

spring: $1.8 ; 4.2$

strike: $1.8 ; 4.2$

team: $1.8 ; 4.2$

ticket: $1.5 ; 1.8$

tips: $1.8 ; 4.2$

tiquetero: $1.5 ; 1.8 ; 4.2$

vernacular: $1.5 ; 1.8 ; 4.2$

vernaculares: $1.5 ; 1.8$

water closet: 1.8

welter: $1.8 ; 4.2$

winch: $1.8 ; 4.2 ; 4.4$

yes man: $1 . .8$ 